\title{
Analysis of Natural Ventilation Performance Gap between Design Stage and Actual Operation of Office Buildings
}

\author{
Xiuzhang $\mathrm{FU}^{1,2, *}$ and Mingzhu $\mathrm{HAN}^{1}$ \\ ${ }^{1}$ School of Architecture, Southeast University, China, People's Republic of \\ ${ }^{2}$ Key Laboratory of Urban and Architectural Heritage Conservation of Ministry of Education, Southeast University, China, \\ People's Republic of
}

\begin{abstract}
Suitable natural ventilation in office buildings can not only reduce energy consumption of air conditioning, but also improve indoor air quality. In the architectural design stage, the effect of natural ventilation design is mainly simulated by CFD simulation software for indoor air speed, pressure, and age of air, etc.. However, during the actual building operation, the indoor natural ventilation effect will be affected by many factors, such as surrounding buildings, indoor layout, window position and open-close status, human behavior, etc., and the natural ventilation performance between design stage and actual operation is often different. In this paper, a typical office building was selected and FloVENT software was used to quantitatively analyse the influence of surrounding buildings, indoor layout, door/window opening conditions on indoor natural ventilation. Field measurement of indoor air flow rates in typical positions in office were carried out under different circumstances. In order to reduce the instantiate influence of outdoor wind speeds, a new index named Wind Speed Ratio(WSR) is put forward.Through comparative analysis of simulated data and measured data. the gap degree in natural ventilation performance between design stage and operation operation is discussed, and results show that the relative errors of the WSR, which could be considered to reflect the performance gap, are about $78.0 \%, 28.7 \%$ and $150 \%$ respectively, under corresponding condition settings of surrounding buildings, indoor layout, and door/window opening.
\end{abstract}

\section{Introduction}

People live in buildings $90 \%$ of their life, therefore, maintaining good indoor air quality is very important for people's health, comfort and high-quality life. Natural ventilation is an important means to guarantee good indoor air quality, reduce indoor temperature in summer and control humid environment by introducing outdoor air. In addition, it also has a great impact on building energy consumption. Relevant research results show that buildings adopting natural ventilation can save building energy consumption by $14 \sim 41 \mathrm{kWh} / \mathrm{m}^{2}$ per year [1].

In the architectural design stage, analysis of natural ventilation can provide information for key design decisions affecting natural ventilation performance (NVP). With the development of natural ventilation simulation technologies, more and more architects can get good predictions of NVP under typical conditions in design stage aided by CFD simulations. Belleri, Lollini and Dutton [2] studied building natural ventilation design by collecting data on occupants' window use, local weather conditions, indoor environment conditions and air change rates of a natural ventilation office building to determine the influence of design parameters on natural ventilation performance prediction. Nomura and Hiyama [3] summarized the literatures on the field study of natural ventilation office buildings, the results show that the natural ventilation performance depends on the architectural design to a large extent. But scholars have found the natural ventilation performance gap between design stage and actual operation through field measurement and CFD numerical simulation. Wilde [4] conducted a preliminary study attempting to conduct a probabilistic investigation of the performance gap between building design stage and actual operation, and suggested to adopt a broad and coordinated method, combine model verification and field study, and improve the collection of predicted data to reduce the performance gap. Walker, Tan and Glicksman [5] took an open three-story office building with atrium as the research object by using the scaled model and numerical simulation. Based on the data of indoor temperature, airflow patterns, wind speed, energy consumption, internal heat gain, number of personnel obtained from 16 months of actual building field measurement, the parameters of the scaled building model' $\mathrm{s}$ experiments thus were used as inputs into a CFD simulation model to compare predicted and measured airflow patterns, temperatures and velocity distributions. In the actual operation of the building, the indoor natural ventilation effect is related to various influencing factors such as surrounding buildings, building position and orientation, indoor furniture, door and window opening and closing, window opening mode and area, outdoor wind direction,

* Corresponding author: foux@seu.edu.cn 
etc. Building simulation tools can theoretically provide natural ventilation performance prediction for designers. However, due to certain limitations of CFD natural ventilation simulation, many architectural design parameters are uncertain, and the expected natural ventilation performance obtained is often too variable and different from the actual operation.

Therefore, this paper mainly discusses the natural ventilation performance gap between design stage and actual operation. Taking a selected office building as example, the paper simulates and analyses the influence of surrounding buildings, indoor layout, door and window opening/closing on the indoor natural ventilation effect, and compares the natural ventilation performance gap between design stage and actual operation in combination with the field study.

\section{Mechanisms and methods}

\subsection{Mechanisms}

Among simulation methods of natural ventilation, the multi-zone model is a good way to analyse and assist the natural ventilation design of buildings by rapidly calculating the natural ventilation information of the

Table 1. Comparison of influencing factors of indoor air flow rate

\begin{tabular}{cc}
\hline Parameter & Design stage \\
\hline $\mathrm{e}$ & Typical values are generally taken. \\
$C_{\mathrm{p}}$ & $\begin{array}{c}\text { Depending on the size and fineness of the modeling zone, wind } \\
\text { direction, wind speed gradient, etc., generally only the analysis } \\
\\
\text { object itself is considered, the dominant wind direction is taken. }\end{array}$ \\
$C_{\mathrm{D}}$ & $\begin{array}{c}\text { Depending on the precision of modeling, normally empty rooms } \\
\text { are generally taken. }\end{array}$ \\
G & Generally, the opening is fully open.
\end{tabular}

main flow fields of buildings through simple formulas. Among them, the local wind pressure coefficient $C_{\mathrm{P}}$ and the opening discharge coefficient $C_{\mathrm{D}}$ are the basis of the natural ventilation calculation using a multi-zone model, $C_{\mathrm{P}}$ determines the surface wind pressure, $C_{\mathrm{D}}$ determines the opening flow resistance. Through derivation, the calculation formula (1) of air flow rate can be obtained. $Q$ is the opening volume flow rate, $\mathrm{m}^{3} / \mathrm{s}, A$ is the opening

area, $\mathrm{m}^{2}$, and $\mathrm{v}_{\mathrm{e}}$ is the outdoor wind speed, $\mathrm{m} / \mathrm{s}$.

$$
Q=C_{\mathrm{D}} \cdot \mathrm{A} \cdot \sqrt{C_{\mathrm{p}}} \cdot v_{\mathrm{e}}
$$

It can be seen that the magnitude of the indoor air flow rate depends on both the local wind pressure coefficient and the opening discharge coefficient, and is influenced by the outdoor wind speed and the opening area. The influences and values of these parameters are also different in the design stage and the actual operation. Comparative analysis under the design and actual operation stages is shown in Table 1. The difference between the two actually determines the natural ventilation performance gap between design stage and actual operation.

Actual operation
Rapid changes.
All wind directions, many cities do not show
obvious dominant wind direction characteristics;
monsoon is obvious.
indoor layout and opening, furniture .

Affected by human behavior, the opening area varies.

of outdoor wind, the paper uses the relative value of "indoor and outdoor wind speed ratio" compare the effect of different conditions on indoor natural ventilation. The definition of "indoor and outdoor wind speed ratio" is the ratio of indoor air speed and outdoor wind speed at the same time and wind direction, in formula (2). Among them, WSR is the ratio of indoor and outdoor wind speed at the same time, $v_{i}$ is the indoor air speed, $\mathrm{m} / \mathrm{s}$, and $\mathrm{v}_{\mathrm{e}}$ is the outdoor wind speed, $\mathrm{m} / \mathrm{s}$.

$$
W S R=\frac{v_{\mathrm{i}}}{v_{\mathrm{e}}}
$$

\subsection{Simulation and measurement}

The paper mainly uses the methods of field investigation, software simulation and field measurement to study the influence of surrounding buildings, indoor layout, door and window opening and closing on indoor natural ventilation effect, taking a office Building(called Yifu) in the campus of Southeast University as the research object. The office building adopts a typical central transportation core-tube structure, with 16 floors, a total height of about $64 \mathrm{~m}$, a width of $27.4 \mathrm{~m}$ from north 
to south, and a length of $33.2 \mathrm{~m}$ from east to west. The third floor is selected as the specific research floor. The room functions mainly include the teacher's office and the student's studio. The building plan is shown in Fig.1.

The CFD software FloVENT is used to carry out numerical simulation on the office building, establishing the surrounding buildings models according to the actual mapping situation, and carrying out detailed modelling on the third floor, as shown in Fig.2. Wind boundary condition input parameters is selected from outdoor weather data monitored by weather stations. In order to study the influence of different factors on the natural ventilation performance gap by combining singlevariable criteria, the air speed values of the measuring point in research room under various conditions are simulated and measured meanwhile, where an assessment criteria, called Relative Error, is defined as fomula (3):

$$
\text { Relative Error }=\frac{W S R_{j}-W S R_{\mathrm{m}}}{W S R_{\mathrm{m}}} \times 100(\%)
$$

Where, $W S R_{j}$ is simulation value of Wind Speed Ratio (WSR) of the measuring point under different condition settings; $W S R_{\mathrm{m}}$ is measurement value of WSR of the measuring point under actual condition.

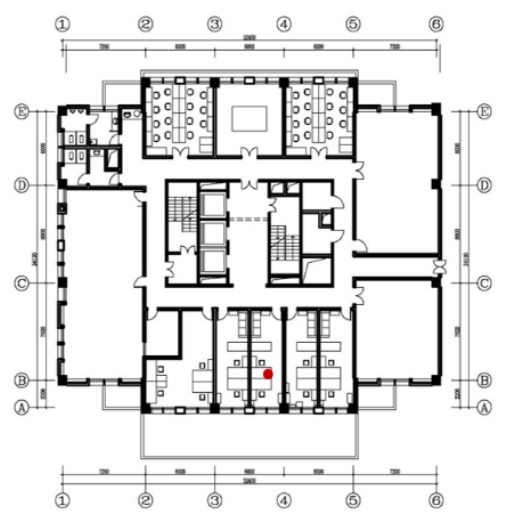

Fig. 1. Three-story plan of Yifu Building (The red dot indicates the research room)

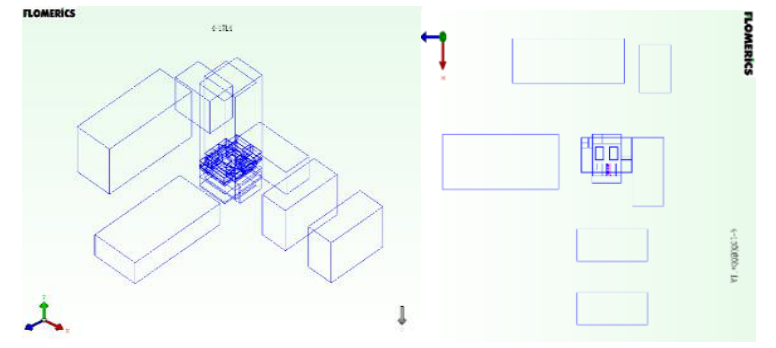

Fig. 2. Three-storey physical model of Yifu Building

In order to compare with the simulated data, the field measurement takes into account both outdoor weather parameters and indoor natural ventilation conditions. A portable weather station placed on the roof of the adjacent building (No.4 in Fig.4) is used to automatically monitor and record outdoor weather data, meanwhile, a handy instrument SWEMA 3000 is used to monitor indoor air speed parameters. The position of measuring point is shown in red dot in Fig.3, the height of measuring point from the ground is $1.12 \mathrm{~m}$.

\section{Results and discussion}

\subsection{Results}

\subsubsection{Surrounding buildings}

When there are other buildings around the target building, the wind environment in the area where the target building is located will change, and only the model of the target building is likely to get inconsistent analysis conclusions with the actual operation. In order to accurately reflect the influence of the surrounding buildings on the wind environment of the target building, when establishing the model for the target building, the target building is considered as the center, and the different surrounding buildings conditions within the radius of $0 \mathrm{~m}, 30 \mathrm{~m}, 50 \mathrm{~m}$ and $100 \mathrm{~m}$ are simulated, and the influence degree of the surrounding buildings on the wind environment of the target building is analyzed. As shown in Fig.4, the surrounding buildings are numbered, the set conditions are summarized in Table 2, where No. E1 E5 stands for different surrounding conditions respectively. The outdoor weather data for simulation is from the weather station recorded on Nov.16, 2017, and the dominant wind direction " $\mathrm{S}$ " with an average wind speed of $1.44 \mathrm{~m} / \mathrm{s}$ on that day is selected.

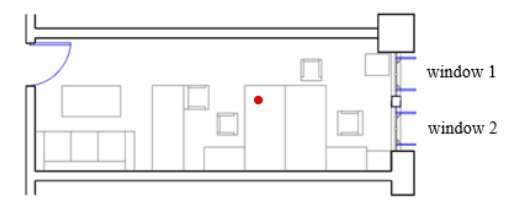

Fig. 3. Schematic diagram of research room (The red dot is field measuring point)

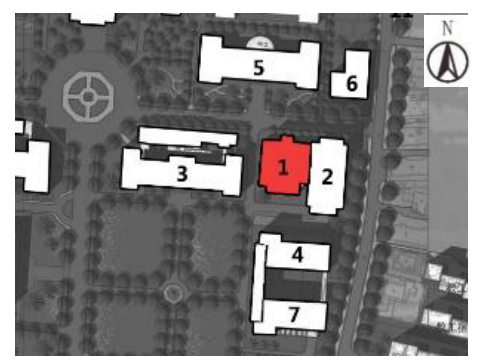

Fig. 4. Numbering of surrounding buildings (No.1 is Yifu Building)

The relative errors of the indoor and outdoor wind speed ratio(WSR) at the measuring point between simulation under different surrounding buildings conditions and measurement under actual condition are shown in Fig.5. When the modelling range only considers the target building(E1), the relative error between the simulated values and the measured values is about $78.0 \%$. When considering surrounding buildings 
within $100 \mathrm{~m}$ of the target building radius, and all doors and windows are set open(E4), the relative error is about $11.2 \%$. With the increase of the fineness of the surrounding buildings model, the simulation value of the indoor and outdoor wind speed ratio at the measuring point is gradually approaching the actual measurement value. It could also be found that the relative error is about $-2.0 \%$ even in actual condition (E5).

Table 2. Conditions setting of surrounding buildings

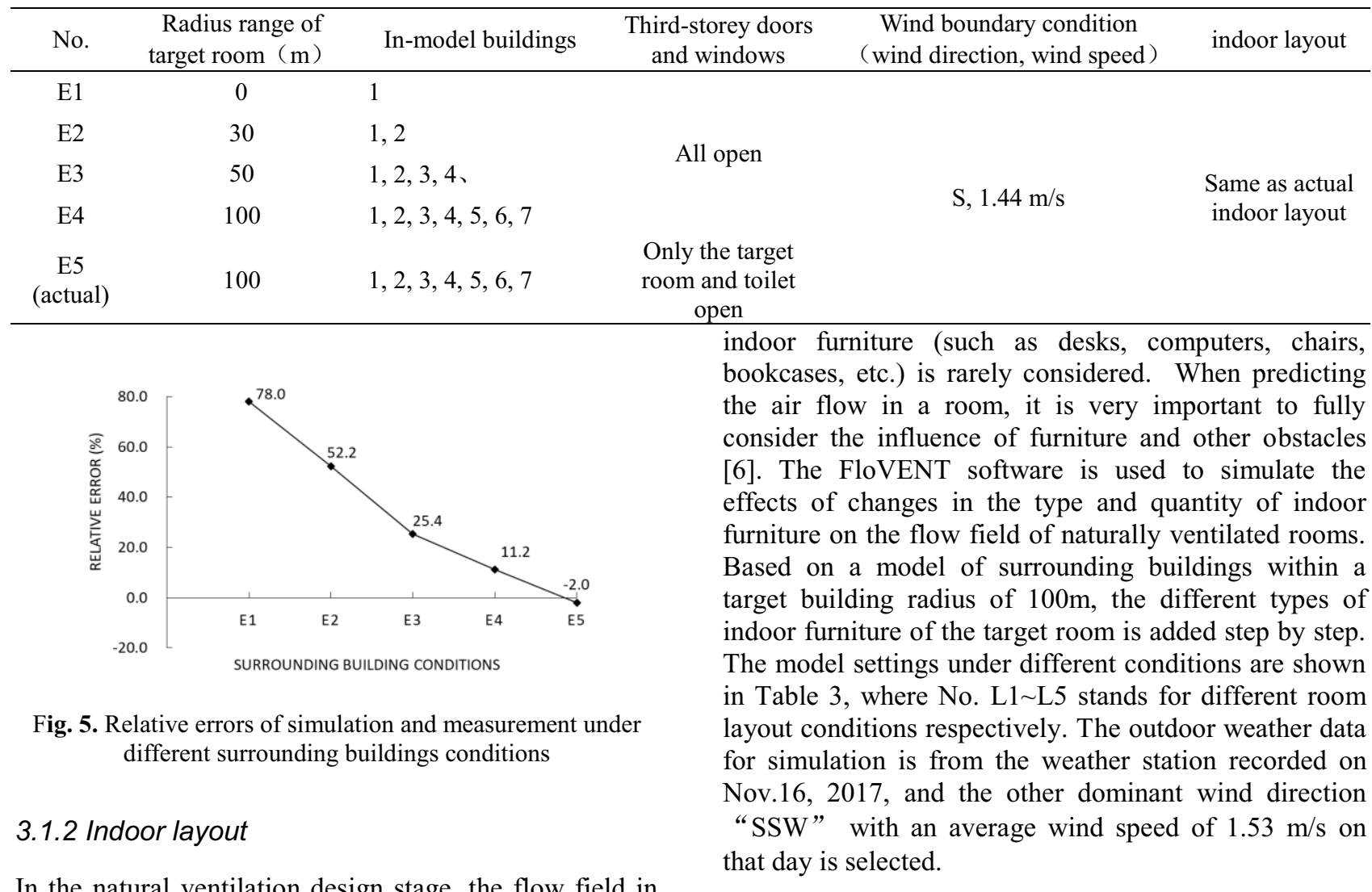

In the natural ventilation design stage, the flow field in an empty room is usually studied, and the influence of

Table 3. Condition setting of indoor layout

\begin{tabular}{|c|c|c|c|c|}
\hline No. & Furniture type & $\begin{array}{l}\text { Third-storey doors and } \\
\text { windows }\end{array}$ & $\begin{array}{l}\text { Wind boundary condition } \\
\text { (wind direction, wind speed) }\end{array}$ & $\begin{array}{l}\text { indoor } \\
\text { layout }\end{array}$ \\
\hline L1 & Empty & \multirow{4}{*}{ all open } & \multirow{5}{*}{$\begin{array}{c}\mathrm{SSW} \\
1.53 \mathrm{~m} / \mathrm{s}\end{array}$} & \multirow{5}{*}{$\begin{array}{c}\text { Same as } \\
\text { actual } \\
\text { indoor } \\
\text { layout }\end{array}$} \\
\hline L2 & bookcase, table & & & \\
\hline L3 & bookcase, table, sofa tea table, chair, cupboard & & & \\
\hline L4 & $\begin{array}{c}\text { bookcase, table, sofa tea table, chair, cup- } \\
\text { board, office supplies }\end{array}$ & & & \\
\hline $\begin{array}{c}\text { L5 } \\
\text { (actual) }\end{array}$ & $\begin{array}{l}\text { bookcase, table, sofa tea table, chair, cup- } \\
\text { board, office supplies }\end{array}$ & $\begin{array}{l}\text { Only the target room } \\
\text { and toilet open }\end{array}$ & & \\
\hline
\end{tabular}

The relative errors of the indoor and outdoor wind speed ratios(WSR) at the measuring point between simulation under different indoor layout conditions and measurement under actual condition are shown in Fig.6. When the room is set to empty(L1), the relative error between the simulated value and the measured value is about $28.7 \%$. When the furniture arrangement is the same as the actual condition, but all doors and windows are set open(L4), the relative error falls down to $11.1 \%$. With the increase of indoor furniture, there is a lowspeed vortex area in the target room. It can be considered that the layout of indoor furniture will affect the natural ventilation effect to a certain extent. It could also be found that the relative error is about $-4.2 \%$ even in actual condition (L5).

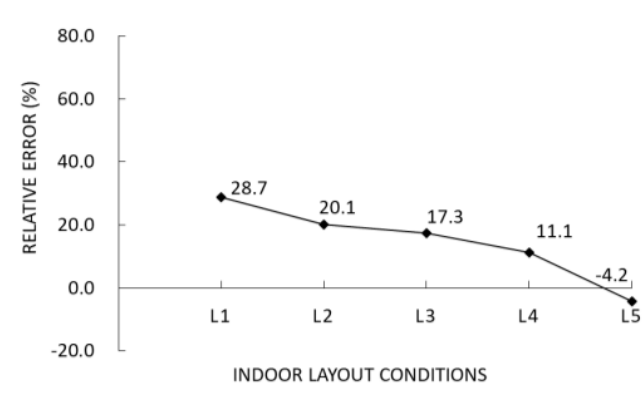

Fig. 6. Relative errors of simulation and measurement under different indoor layout conditions 


\subsubsection{Door/window opening}

After the building is actually put into use, the opening and closing of doors and windows is closely related to human behavior, which directly affects the indoor actual natural ventilation effect. However, during the building design simulation stage, designers normally default that the doors and windows of the room are all open, thus causing the gap between design stage and actual operation. In order to study the natural ventilation effect of the target room under different door and window opening and closing conditions, where the surrounding buildings within a radius of $100 \mathrm{~m}$ are modelled in detail, the same indoor layout as the actual one is considered, and the doors/windows of other rooms on the third floor are closed. The target room is simulated under different door/window opening or closing conditions. Table 4 shows the different condition settings for simulation, where No. W1 W4 stands for different door/window opening status respectively. The outdoor weather data for simulation is from the weather station recorded on Dec. 2, 2017, the dominant wind direction "SW" with an average wind speed of $0.96 \mathrm{~m} / \mathrm{s}$ on that day is selected. In addition, the corresponding field measurement is performed under different condition above, and the relative error between the simulation and measurement is analyzed.

Table 4. Conditions setting of door and window opening and closing

\begin{tabular}{cccc}
\hline No. & $\begin{array}{c}\text { Door and Window Condition } \\
\text { (Other rooms are closed })\end{array}$ & $\begin{array}{c}\text { Wind boundary condition } \\
\text { (wind direction, wind speed })\end{array}$ & Model setting \\
\hline W1 & Door and the windows1\&2 open & & Surrounding buildings within radius of 100m \\
W2 & Door and window1 open & SW & \\
W3 & Door and window2 open & $0.96 \mathrm{~m} / \mathrm{s}$ & \\
W4 & Door closed and window1\&2 open & & \\
\hline
\end{tabular}

The relative errors of the indoor and outdoor wind speed ratio at the measuring point between simulation and measurement under different door/window opening or closing conditions are shown in Fig.7. When opening the door and two windows(W1), the relative error is about $-2.4 \%$, when opening the door and only one window(W2 or W3), the relative error is about $-1.0 \% \sim$ $1.5 \%$, and when closing the door and opening the windows(W4), the relative error is about $-7.0 \%$. When the door is opened, the airflow enters the room through the window and flows out through the door to form cross ventilation, while when the door is closed, the room can only perform single-side natural ventilation through the window, thus greatly reducing the indoor natural ventilation effect.

In addition, when the office building is actually used, the office room is mostly in the state of door closing like condition $\mathrm{W} 4$, and the design expectation simulation is more inclined to open the door and window like condition W1. The WSR becomes from 0.320 in W1 simulation condition to 0.128 , which is measured in actual condition(W4), and the relative error between expectation(W1) and operation(W4) is up to $150 \%$ (Table 5).

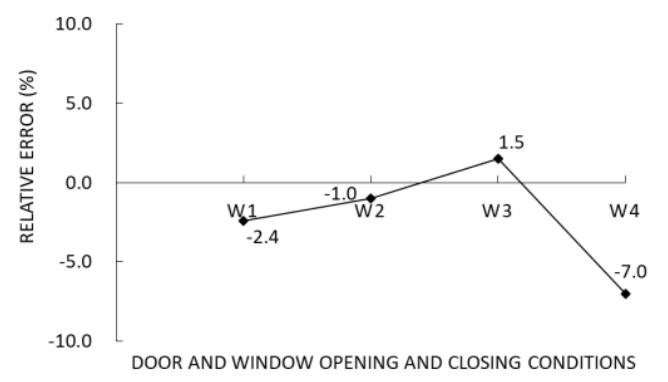

Fig. 7. Relative errors of simulation and measurement under different door/window opening or closing conditions

\subsection{Discussion}

In order to further explore the relative errors between simulation and measurement, the gap degree between simulation and measurement under different surrounding buildings, indoor layout, door/window opening or closing conditions is compared and analyzed respectively. Their relative errors are shown in Table 5. The simulated and measured relative error under different influencing factors ranges from $-7.0 \%$ to $1.5 \%$. It can be considered that the simulated values obtained when taking these factors into account are in good agreement with the measured values. In addition, according to the comparison of the relative errors among different influencing factors, the relative error is the largest under the door/window opening or closing conditions, especially when close the door and open the windows, followed by the influence of indoor layout, and the relative error between the two is the smallest under the influence of surrounding buildings. Therefore, based on the comparative analysis of the performance gap on both sides in the paper, in order to make the simulation results more consistent with the actual operation, during the design stage, the designer should consider several conditions of door and window opening and closing, and can ensure the thermal comfort of natural ventilation in the room under different conditions. The furniture in the architectural plan should also be included in the software modelling process. Considering at least surrounding buildings within a radius of $100 \mathrm{~m}$ of the target building to effectively reduce the natural ventilation performance gap between design stage and actual operation.

In this paper, the natural ventilation performance gap mechanism between design stage and actual operation is analyzed by using the method of combining simulation 
and field measurement, and the degree of influence of different factors on natural ventilation performance is compared. However, most of the indoor and outdoor wind speed ratio data obtained from the simulation are smaller than those obtained from the field measurement, which may be related to the limitations of software simulation. In addition, the field measurement time is short, and the research object does not cover all rooms on the whole floor, resulting in incomplete experimental data. Whether the proposed gap mechanism is applicable to all buildings needs further verification. In the subsequent study, it is necessary to select multiple types and multiple buildings to carry out a wider range of field measurement and the simulation, to verify and improve the gap mechanism of natural ventilation performance, to be suitable for most natural ventilation buildings, and to propose a more comprehensive design strategy to reduce the performance gap.

Table 5. Comparison of indoor and outdoor wind speed ratio at measuring points

\begin{tabular}{ccccccc}
\hline \multirow{2}{*}{ WSR } & \multicolumn{7}{c}{ Conditions } \\
\cline { 2 - 7 } & E5 & L5 & W1 & W2 & W3 & W4 \\
\hline Simulation & 0.289 & 0.276 & 0.320 & 0.292 & 0.276 & 0.119 \\
Measurement & 0.295 & 0.289 & 0.328 & 0.295 & 0.272 & 0.128 \\
Relative error, \% & -2.03 & -4.15 & -2.44 & -1.02 & 1.47 & -7.03 \\
\hline
\end{tabular}

\section{Conclusions}

Based on the natural ventilation performance gap mechanism, the paper takes a typical office building as an example to carry out a comparative analysis between numerical simulation and field measurement, explores the impact of different conditions of surrounding buildings, indoor layout and door/window opening status on indoor natural ventilation. The relative error of indoor and outdoor wind speed ratios(WSR) between simulation and measurement under the influence of door /window opening condition is up to $150.0 \%$, the relative error in considering only the target building without surrounding buildings is $78.0 \%$, and the relative error of empty indoor layout, neglecting the actual furniture arrangement, is $28.7 \%$. The natural ventilation performance gap between design stage and actual operation is mainly due to the precision of the analysis model. Therefore, in the design stage, it is necessary to consider typical door/window opening modes in building operation, establish surrounding buildings as fine as possible, and reflect the influencing factors such as indoor layout and weather data in the building model to minimize the natural ventilation performance gap between design stage and actual operation.

\section{References}

1. S. Irving, B. Ford, D. Etheridge, Natural ventilation in non-domestic buildings, (2000).

2. A. Belleri, R. Lollini, S.M. Dutton, Build. Environ. 81, 123-138 (2014).

3. M. Nomura, K. Hiyama, Renew. Sust. Energ. Rev. 74, 746-754 (2017).

4. P.D. Wilde, Autom. Constr. 41, 40-49 (2014).

5. C. Walker, G. Tan, L. Glicksman, Energy Build. 43, 2404-2413 (2011).

6. P.V. Nielsen, Indoor Air. 14, 134-143 (2004). 